\title{
Hemodynamic effects of acute hyperoxia: systematic review and meta-analysis
}

\author{
Bob Smit ${ }^{1 *}$ (D, Yvo M. Smulders ${ }^{2}$, Johannes C. van der Wouden ${ }^{3}$, Heleen M. Oudemans-van Straaten ${ }^{1}$ \\ and Angelique M. E. Spoelstra-de Man'1
}

\begin{abstract}
Background: In clinical practice, oxygen is generally administered to patients with the intention of increasing oxygen delivery. Supplemental oxygen may, however, cause arterial hyperoxia, which is associated with hemodynamic alterations. We performed a systematic review and meta-analysis of the literature to determine the effect of hyperoxia on central hemodynamics and oxygen delivery in healthy volunteers and cardiovascular-compromised patients.

Methods: PubMed and EMBASE were searched up to March 2017. Studies with adult humans investigating changes in central hemodynamics or oxygen delivery induced by acute normobaric hyperoxia were included. Studies focusing on lung, retinal, or brain parameters were not included. We extracted subject and oxygen exposure characteristics, indexed and unindexed values for heart rate, stroke volume, cardiac output, mean arterial pressure (MAP), systemic vascular resistance, and oxygen delivery during normoxia and hyperoxia. For quantitative synthesis of the data, a random-effects ratio of means (RoM) model was used.
\end{abstract}

Results: We identified 33 studies with 42 datasets. Study categories included healthy volunteers ( $n=22$ datasets), patients with coronary artery disease (CAD; $n=6)$, heart failure $(H F ; n=6)$, coronary artery bypass graft (CABG; $n=3)$ and sepsis $(n=5)$. Hyperoxia (arterial oxygen tension of 234-617 mmHg) reduced cardiac output (CO) by 10-15\% in both healthy volunteers ( $-10.2 \%$, $95 \%$ confidence interval (Cl) $-12.9 \%$ to $-7.3 \%)$ and CAD $(-9.6 \%, 95 \% \mathrm{Cl}-12.3 \%$ to $-6.9 \%)$ or HF patients $(-15.2 \%$, $95 \% \mathrm{Cl}-21.7 \%$ to $-8.2 \%)$. No significant changes in cardiac output were seen in CABG or septic patients (-3\%). Systemic vascular resistance increased remarkably in patients with heart failure (24.6\%, 95\% Cl 19.3\% to 30.1\%). In healthy volunteers, and those with CAD and CABG, the effect was smaller (11-16\%) and was virtually absent in patients with sepsis $(4.3 \%, 95 \% \mathrm{Cl}-3.2 \%$ to $12.3 \%)$. No notable effect on MAP was found in any group (2-3\%). Oxygen delivery was not altered by hyperoxia. Considerable heterogeneity existed between study results, likely due to methodological differences.

Conclusions: Hyperoxia may considerably decrease cardiac output and increase systemic vascular resistance, but effects differ between patient categories. Heart failure patients were the most sensitive while no hemodynamic effects were seen in septic patients. There is currently no evidence supporting the notion that oxygen supplementation increases oxygen delivery.

Keywords: Hyperoxia, Oxygen, Hemodynamics, Systematic review, Meta-analysis

\footnotetext{
* Correspondence: bob_smit@xs4all.nl

${ }^{1}$ Department of Intensive Care, VU University Medical Center, De Boelelaan

1117, 1007, MB, Amsterdam, the Netherlands

Full list of author information is available at the end of the article
} 


\section{Background}

In critical care and emergency medicine, oxygen is frequently administered to ensure satisfactory oxygen delivery to organs. To correct or prevent hypoxia, oxygen is often supplemented superfluously which may lead to hyperoxia (a higher than normal arterial partial pressure of oxygen $\left(\mathrm{P}_{\mathrm{a}} \mathrm{O}_{2}\right)$ ).

Both negative and positive clinical consequences are ascribed to hyperoxia. It is associated with increased intensive care unit (ICU) mortality [1-3] and increased myocardial [4] and cerebral infarction size [5]. However, hyperoxia has also been associated with beneficial effects such as improved organ function after cardiac arrest [6] and, in animal models, hyperoxia has been shown to induce a redistribution of blood flow to vital organs $[7,8]$.

The cardiovascular effects of oxygen could play an important role in the aforementioned clinical outcomes. Reported hemodynamic effects include peripheral vasoconstriction and reduced cardiac output (CO) [9]. These effects may exacerbate pre-existing perfusion disturbances and, therefore, reduce tissue oxygen delivery [10]. On the other hand, hyperoxic peripheral vasoconstriction may improve circulatory shock, potentially reducing the need for fluid and vasopressor resuscitation $[11,12]$.

The magnitude of hyperoxia-induced hemodynamic alterations is currently unclear, as is the generalizability of the effects to different types of patients. In this systematic review and meta-analysis, we aim to provide an overview of the evidence of changes in hemodynamics and oxygen delivery induced by oxygen supplementation in healthy volunteers and patients with cardiovascular disease or sepsis.

\section{Methods}

\section{Search strategy}

We searched PubMed and EMBASE for eligible studies published up to March 2017. The search query consisted of various keywords related to the domains of hemodynamics, hyperoxia, and humans (Additional file 1). These separate domains were combined with the AND operator. References of included studies were screened for publications that were not identified in the search.

\section{Study selection}

Studies were screened in three separate phases. Phase 1 consisted of screening based on title by one of the authors (BS); obviously irrelevant articles were excluded. During phase 2, two authors (BS, AMESdM) selected articles based on the abstract for full text screening in phase 3 . Inclusion criteria were studies with adults that investigated the effect of hyperoxia induced by short-term $(<6 \mathrm{~h})$ inhalation of oxygen on systemic hemodynamic parameters (heart rate (HR), mean arterial pressure (MAP), $\mathrm{CO}$, stroke volume (SV), systemic vascular resistance (SVR), and oxygen delivery $\left.\left(\mathrm{DO}_{2}\right)\right)$ in comparison with normoxia. For studies with healthy volunteers, normoxia was defined as a fraction of inspired oxygen $\left(\mathrm{F}_{\mathrm{I}} \mathrm{O}_{2}\right)$ of $21 \%$. For studies with patients, a higher baseline $\mathrm{F}_{\mathrm{I}} \mathrm{O}_{2}$ was accepted before hyperoxia induction. Studies had to report on a combination of heart rate and stroke volume or cardiac output, or on oxygen delivery. We excluded studies involving hyper- or hypobaria, chronic lung disease, sleep disorders (e.g., apnea studies), resuscitation (e.g., use of oxygen after cardiac arrest), pregnancy or childbirth, and changes in the inspired gas fraction other than oxygen and long-term hyperoxia ( $>6 \mathrm{~h}$ ). Studies on the effect of hyperoxia during exercise were included only if they contained data during rest. We did not include studies measuring solely lung, retinal, or brain parameters.

\section{Data extraction}

We extracted the following data from each study: the first author's last name, publication year, number of subjects, method of oxygen administration, main measurement method for cardiac indices, $\mathrm{F}_{\mathrm{I}} \mathrm{O}_{2}, \mathrm{P}_{\mathrm{a}} \mathrm{O}_{2}$, and exposure time. For the parameters of interest (HR, SV, $\mathrm{CO}, \mathrm{MAP}, \mathrm{SVR}, \mathrm{DO}_{2}$ ) we extracted the mean and standard deviation (SD) or standard error of the mean (SEM) during normoxia and hyperoxia, correlation coefficients, and change from baseline along with SD/SEM where available. Both indexed and unindexed parameters (e.g., cardiac output and cardiac index) were extracted. If sufficient patient-level data were reported, missing parameters were calculated with conventional formulae [13]. If a study investigated multiple oxygen dosages, we included only the highest dose in this analysis. If measurements were made at multiple timepoints, we extracted the data from the timepoint that was closest to that of the mean of other studies.

\section{Risk of bias}

For the assessment of the risk of bias of the included studies, we used a modified version of a quality assessment tool for pre-post studies without a control group (see Additional file 2) [14]. The tool consists of 11 questions which pertain to the presence of an adequate description of the study objective, study population, sample size calculation, intervention and its verification, the application of randomization, the stability of the study subjects, possible carry-over effects, participant blinding, assessor blinding, and, finally, statistics and statistical tests. Possible answers were "yes" (low risk of bias), "no" (high risk of bias), "uncertain" (uncertain risk of bias) and "not applicable".

\section{Data synthesis and analysis}

Effect sizes of the individual studies are presented as the ratio of means (RoM) with 95\% confidence intervals (CIs) [15], adjusted for correlated measurements (see 
Additional file 3), and were pooled by a random effects model [16]. For ease of interpretation, we converted RoM to percentage change (\%) using the following formula: $(\operatorname{RoM}-1) \times 100$. Due to the obvious health differences between volunteers and patients, studies with either population were analyzed separately. Heterogeneity was assessed by the $I^{2}$ statistic and is reported along with its 95\% CI [17]. For studies that did not report correlation coefficients between pre- and post-test measurements, we imputed the average correlation coefficient from other studies. A sensitivity analysis was performed to test the influence of the imputed coefficients. The likelihood of publication bias was assessed by visual inspection of the funnel plot for studies measuring CO. All calculations were made with Microsoft Excel [18]. Graphs were made using Graphad Prism 7.0 (GraphPad Software, Inc., La Jolla, USA).

\section{Results}

\section{Search results and study characteristics}

We found 6893 articles in the online databases of PubMed and EMBASE (Fig. 1). After screening and eligibility assessment, a total of 33 studies were included for this meta-analysis, reporting measurements in healthy volunteers ( $n=19$ studies), patients with coronary artery disease (CAD; $n=6)$, heart failure (HF; $n=5)$, postcoronary artery bypass graft $(\mathrm{CABG})$ surgery $(n=3)$, or sepsis $(n=3)$. From these studies, 42 datasets could be extracted (see Table 1 for an overview of the study characteristics from studies with healthy volunteers, and Table 2 for studies with patients). Other patient populations found, but excluded from this analysis, were patients with pulmonary arterial hypertension and cirrhosis. The included studies were published between 1958 and 2017, with the majority (55\%) being published after 2000 . The

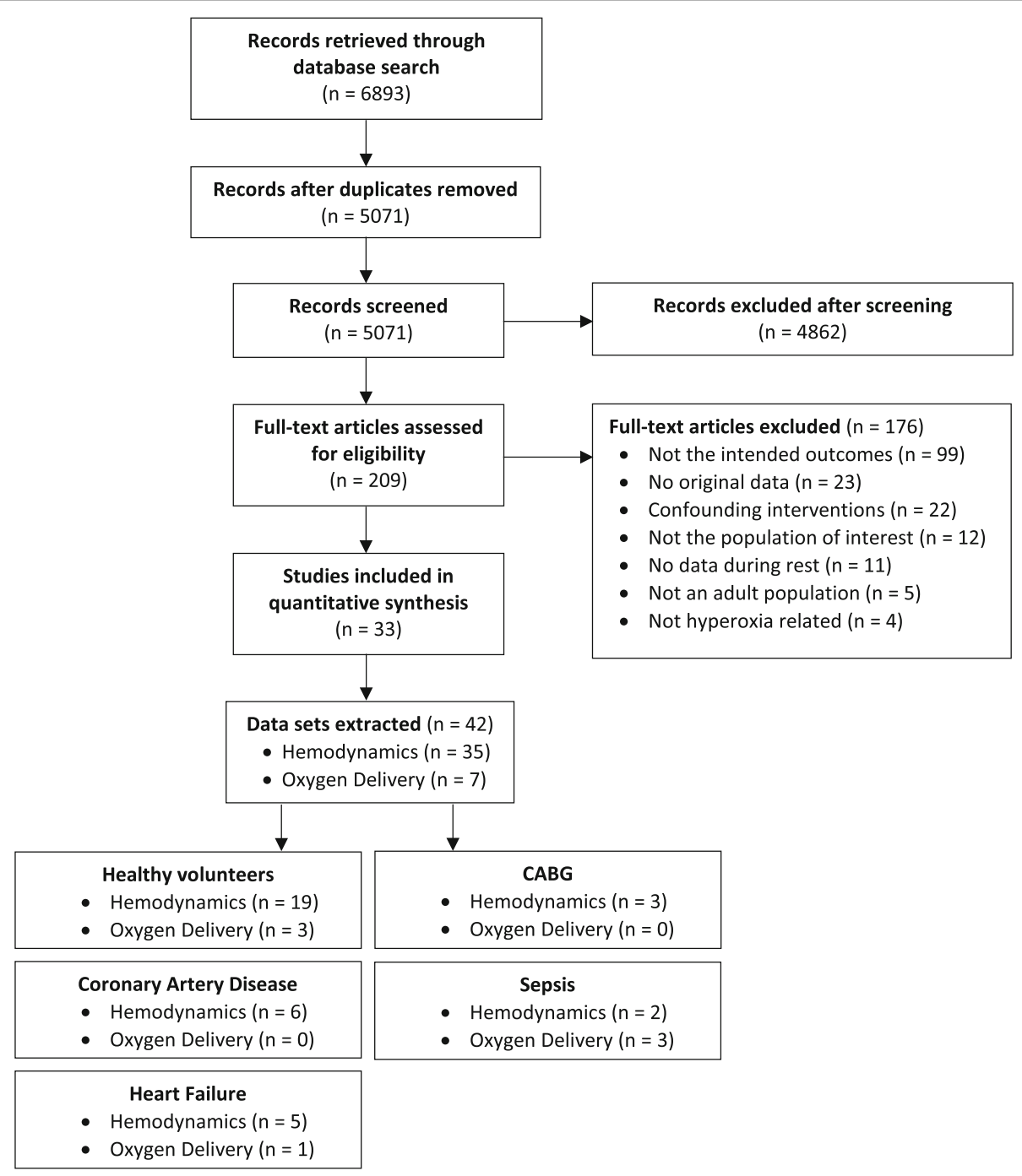

Fig. 1 Flow diagram of the included and excluded studies. The flow chart for the inclusion and exclusion of studies for the current meta-analysis. $C A B G$ coronary artery bypass graft 
Table 1 Study overview for healthy volunteers

\begin{tabular}{|c|c|c|c|c|c|c|c|c|c|}
\hline Study & Year & Age (years) & Subjects ( $n / n$ male) & $\begin{array}{l}\text { Administration } \\
\text { (modality) }\end{array}$ & Exposure (min) & $\begin{array}{l}\text { Intervention* } \\
\text { (baseline/ } \mathrm{O}_{2} \text { ) }\end{array}$ & $\begin{array}{l}\text { Measurement } \\
\text { (method) }\end{array}$ & $\mathrm{HD}$ & $\mathrm{DO}_{2}$ \\
\hline Barrat-Boyes [53] & 1958 & 28 & $20 / N R$ & Mouth piece & $19-60$ & $0.21 / 1.0$ & Fick (blood) & $\checkmark$ & \\
\hline Daly [20] & 1962 & $21-32$ & $9-15 / \mathrm{NR}$ & Mouth piece & 10 & $0.21 / 1.0$ & Dye dilution & $\checkmark$ & \\
\hline Foster [49] & 1969 & 44 & $5 / N R$ & Head tent & 15 & $78 / 269$ & Dye dilution & $\checkmark$ & \\
\hline Andersen [28] & 1970 & $15-59$ & $5-13 / \mathrm{NR}$ & NR & 10 & $87 / 548$ & Dye dilution & $\checkmark$ & $\checkmark$ \\
\hline Karetzky [26] & 1971 & 21 & $8-14 / 1$ & Mouth piece & 15 & $92 / 617$ & Fick (gas) & $\checkmark$ & $\checkmark$ \\
\hline Kenmure [54] & 1972 & NR & $20 / 20$ & NIV mask & 45 & $91 / 537$ & Dye dilution & $\checkmark$ & \\
\hline Harten [55] & 2003 & 35 & $15 / 8$ & Face mask & 5 & $0.21 / 1.0$ & Impedance & $\checkmark$ & \\
\hline Smit [56] & 2003 & 46 & $7 / 6$ & Mouth piece & 10 & $0.21 / 1.0$ & MRI & $\checkmark$ & \\
\hline Waring [57] & 2003 & 28 & $8 / 5$ & Non-rebreather & 10 & $0.21 / 1.0$ & Impedance & $\checkmark$ & \\
\hline Anderson [58] & 2005 & 37 & $30 / 18$ & Non-rebreather & 5 & $0.21 / 1.0$ & Impedance & $\checkmark$ & \\
\hline Rousseau [59] & 2005 & 26 & $12 / 12$ & Non-rebreather & 15 & $0.21 / 1.0$ & Cardiac echo & $\checkmark$ & \\
\hline Bak [9] & 2007 & 31 & $9 / 7$ & Non-rebreather & 15 & $0.21 / 1.0$ & Cardiac echo & $\checkmark$ & \\
\hline Ley [60] & 2007 & 26 & $10 / 5$ & Non-rebreather & 5 & $0.21 / 1.0$ & MRI & $\checkmark$ & \\
\hline Kim [61] & 2008 & $22-34$ & $20 / 8$ & Face mask & 30 & $0.21 / 1.0$ & Volume clamp & $\checkmark$ & \\
\hline Bodetoft [27] & 2011 & $26-65$ & $16 / 8$ & Non-rebreather & 15 & $88 / 383$ & MRI & $\checkmark$ & $\checkmark$ \\
\hline Gole [35] & 2011 & 32 & $10 / 10$ & Non-rebreather & 15 & $0.21 / 1.0$ & Cardiac echo & $\checkmark$ & \\
\hline Gao [62] & 2012 & 27 & $8 / 4$ & Non-rebreather & 10 & $0.21 / 1.0$ & Cardiac echo & $\checkmark$ & \\
\hline Sinski [63] & 2014 & 40 & $11 / 11$ & Face mask & 20 & $0.21 / 1.0$ & Impedance & $\checkmark$ & \\
\hline Fagoni [64] & 2015 & 41 & $19 / 16$ & NR & 10 & $0.21 / 1.0$ & Volume clamp & $\checkmark$ & \\
\hline
\end{tabular}

Studies are sorted based on year of publication

Age is reported as mean or range

* A value $>1.0$ indicates an arterial partial pressure of oxygen $\left(\mathrm{P}_{2} \mathrm{O}_{2}\right)$ in $\mathrm{mmHg}$; values $<1$ indicate the fraction of oxygen in the inhaled gas

$D \mathrm{O}_{2}$ oxygen delivery, $\mathrm{HD}$ hemodynamics, $M R I$ magnetic resonance imaging, NIV noninvasive ventilation, $N R$ not reported

study population sizes were relatively small, ranging between 5 and 35 subjects. Oxygen was most frequently delivered by means of a non-rebreather mask for 5-60 min. Other modalities included a regular face mask, mouth piece, or head tent. In three studies, the modality for oxygen delivery was not mentioned. Arterial oxygen tensions were available for $50 \%$ of the datasets $(18 / 36)$. Oxygen supplementation led to average $\mathrm{P}_{\mathrm{a}} \mathrm{O}_{2}$ of 269-617 $\mathrm{mmHg}$ in healthy volunteers, 234-604 $\mathrm{mmHg}$ in CAD patients, 312-326 mmHg in patients with HF, 390-450 $\mathrm{mmHg}$ in patients after CABG surgery, and 350-416 $\mathrm{mmHg}$ in patients with sepsis. In the studies with the critically ill, all patients were intubated. In healthy volunteers, hemodynamic measurements were performed with invasive techniques (thermo- and dye dilution) up until 1972. Afterwards, noninvasive techniques such as ultrasound and bio-impedance were used. In studies with patients, all systemic hemodynamic measurements were performed invasively, except for one [19] which used bio-impedance.

\section{Missing correlation coefficients}

There were no studies that reported the correlation coefficient between measurements during normoxia and hyperoxia. However, some reported individual data from which these coefficients could be calculated. The average of the calculated coefficients was then used for the remaining studies and for the primary analysis. This resulted in correlation coefficients of 0.95, 0.93, 0.79, 0.95, 0.87, and 0.97 for HR [20-24], SV/SV index (SVI) [20-22, 24], CO/cardiac index (CI) [20-22, 24, 25], MAP [20-24], SVR/SVR index (SVRI) [20-24], and $\mathrm{DO}_{2}$ [22], respectively. The sensitivity analyses showed that the pooled effect size did not change significantly for any of the parameters when lower correlation coefficients $(0.7$ or 0.5$)$ were used.

\section{Risk of bias}

See Additional file 2 for an overview of the risk of bias scores. Objectives were clearly described in all studies and the study populations was adequately described in most. Sample-size calculations were not reported in the majority of studies. In studies with healthy volunteers, the magnitude of the intervention was verified by measuring the arterial oxygen tension in only 5/19 studies. Two used the transcutaneous oxygen tension as an indication for the change in $\mathrm{P}_{\mathrm{a}} \mathrm{O}_{2}$ after oxygen inhalation. The majority of the studies with patients did measure $\mathrm{P}_{\mathrm{a}} \mathrm{O}_{2}$ (13/17). Randomization (order of supplying air or oxygen) was applied in only a few studies. The blinding of either the assessor or the participant was not or 
Table 2 Study overview for patients

\begin{tabular}{|c|c|c|c|c|c|c|c|c|c|}
\hline Study & Year & Age (years) & Subjects ( $n / n$ male) & $\begin{array}{l}\text { Administration } \\
\text { (modality) }\end{array}$ & Exposure (min) & $\begin{array}{l}\text { Intervention* } \\
\text { (baseline } / \mathrm{O}_{2} \text { ) }\end{array}$ & $\begin{array}{l}\text { Measurement } \\
\text { (method) }\end{array}$ & $\mathrm{HD}$ & $\mathrm{DO}_{2}$ \\
\hline \multicolumn{10}{|c|}{ Coronary artery disease } \\
\hline Thomas [21] & 1965 & 61 & $6 / 6$ & Face mask & 20 & $66 / 276$ & Dye dilution & $\checkmark$ & \\
\hline Foster [49] & 1969 & $N R$ & $16 / N R$ & Head tent & 15 & $68 / 234$ & Dye dilution & $\checkmark$ & \\
\hline Ganz [65] & 1972 & 56 & $9 / 7$ & Non-rebreather & 7 & $75 / 403$ & Dye dilution & $\checkmark$ & \\
\hline Lecerof [66] & 1974 & $46-59$ & $8 / 8$ & NR & 20 & $0.21 / 604$ & Dye dilution & $\checkmark$ & \\
\hline Saadjian [50] & 1999 & 62 & $20 / 15$ & Non-rebreather & 30 & $77 / 355$ & Thermodilution & $\checkmark$ & \\
\hline Mak [67] & 2001 & 63 & $12 / 10$ & Non-rebreather & 20 & $78 / 358$ & Thermodilution & $\checkmark$ & \\
\hline \multicolumn{10}{|l|}{ Heart failure } \\
\hline Daly [22] & 1963 & $35-79$ & 15/NR & Non-rebreather & 10 & $0.21 / 1.0$ & Dye dilution & $\checkmark$ & $\checkmark$ \\
\hline Haque [51] & 1996 & 50 & $10 / 8$ & Non-rebreather & 20 & $0.21 / 1.0$ & Thermodilution & $\checkmark$ & \\
\hline Saadjian [50] & 1999 & 68 & $35 / 26$ & Non-rebreather & 30 & $75 / 326$ & Thermodilution & $\checkmark$ & \\
\hline Mak [67] & 2001 & 62 & $16 / 15$ & Non-rebreather & 20 & $78 / 312$ & Thermodilution & $\checkmark$ & \\
\hline Park [19] & 2010 & 66 & $13 / 13$ & Non-rebreather & 15 & $0.21 / 1.0$ & Impedance & $\checkmark$ & \\
\hline \multicolumn{10}{|c|}{ Intensive care unit - coronary artery bypass graft } \\
\hline Kuttila [32] & 1990 & 52 & $8 / 8$ & Intubated & 15 & $150 / 450$ & Thermodilution & $\checkmark$ & \\
\hline Harten [33] & 2005 & 64 & $15 / 11$ & Intubated & 10 & $138 / 1.0$ & Dye dilution & $\checkmark$ & \\
\hline Helmerhorst [34] & 2017 & 63 & $22 / 17$ & Intubated & 15 & $84 / 390$ & Waveform & $\checkmark$ & \\
\hline \multicolumn{10}{|c|}{ Intensive care unit - sepsis } \\
\hline Reinhart $^{\ddagger}$ [29] & 1991 & $N R$ & $20 / N R$ & Intubated & 30 & $113 / 402$ & Thermodilution & $\checkmark$ & $\checkmark$ \\
\hline Reinhart [30] & 1995 & 53 & $19 / 13$ & Intubated & 30 & $106 / 416$ & Thermodilution & $\checkmark$ & $\checkmark$ \\
\hline Rossi [10] & 2007 & 52 & $14 / 7$ & Intubated & 20 & $102 / 350$ & Brachial echo & & $\checkmark$ \\
\hline
\end{tabular}

Studies are sorted based on year of publication and grouped by study population

Age is reported as mean or range

* A value $>1.0$ indicates an arterial partial pressure of oxygen $\left(\mathrm{P}_{\mathrm{a}} \mathrm{O}_{2}\right)$ in $\mathrm{mmHg}$; values $<1$ indicate the fraction of oxygen in the inhaled gas

* 11 patients had 'other cardiorespiratory insufficiencies'

$D \mathrm{O}_{2}$ oxygen delivery, $\mathrm{HD}$ hemodynamics, $M R I$ magnetic resonance imaging, $N R$ not reported, $P_{a} \mathrm{O}_{2}$ partial pressure of oxygen

inadequately described in most studies. Funnel plots revealed no evidence of publication bias.

\section{Meta-analysis}

Figure 2 displays the summary effect sizes for heart rate, stroke volume, cardiac output, mean arterial pressure, systemic vascular resistance, and oxygen delivery for studies with healthy volunteers, and CAD, heart failure, post-CABG, and septic patients. Additional file 4 shows the forest plots with the individual studies for each subject group.

Oxygen inhalation caused a reduction in heart rate between 6.5 and $2.6 \%$. These changes were seen in healthy volunteers $(-6.5 \%, 95 \% \mathrm{CI}-8.1 \%$ to $-5.0 \%, n=19$ datasets), CAD patients $(-4.7 \%, 95 \%$ CI $-7.9 \%$ to $-1.5 \%, n=6)$, and CABG patients $(-2.6 \%, 95 \% \mathrm{CI}-4.2 \%$ to $-1.0 \%, n=3)$. Effects of hyperoxia on heart rate in heart failure $(-5.3 \%, 95 \%$ CI $-11.4 \%$ to $1.3 \%, n=5)$ and sepsis patients $(1.3 \%, 95 \% \mathrm{CI}$ $-3.6 \%$ to $6.4 \%, n=2$ ) were not statistically significant.

Stroke volume was measured in most studies with healthy volunteers $(n=17$ datasets) and those with CAD $(n=4)$ and HF patients $(n=5)$, but not sufficiently in studies with post-CABG $(n=1)$ or septic patients $(n=0)$. After oxygen supplementation, stroke volume decreased by $3 \%(95 \% \mathrm{CI}-5.7 \%$ to $-0.3 \%)$ and $8.6 \%(95 \% \mathrm{CI}-11.5 \%$ to $-5.7 \%)$ in healthy volunteers and heart failure patients, respectively. No effect on stroke volume was seen in CAD patients $(-2.7 \%, 95 \% \mathrm{CI}-5.7 \%$ to $0.4 \%, n=4)$.

Oxygen supplementation reduced cardiac output in all nonhospitalized individuals. The effect ranged from $-10.2 \%$ (95\% CI $-12.9 \%$ to $-7.3 \%, n=18$ studies) in healthy volunteers to $-9.6 \%(95 \% \mathrm{CI}-12.3 \%$ to $-6.9 \%, n=6)$ in CAD patients and $-15.2 \%(95 \% \mathrm{CI}-21.7 \%$ to $-8.2 \%, n=5)$ in heart failure patients. Cardiac output did not decrease significantly in post-CABG $(-2.8 \%, 95 \% \mathrm{CI}-9.6 \%$ to $4.6 \%, n=3)$ or sepsis patients $(-2.5 \%, 95 \% \mathrm{CI}-8.9 \%$ to $4.3 \%, n=2)$.

Mean arterial pressure increased by $2 \%$ ( $95 \%$ CI $0.2 \%$ to $3.9 \%, n=16$ datasets) and $2.5 \%$ (95\% CI $1.0 \%$ to $3.9 \%, n=4)$ in healthy volunteers and CAD patients, respectively. No statistically significant change in MAP was seen in patients with heart failure $(2.7 \%$, $95 \%$ CI $-2.1 \%$ to $7.7 \%, n=4)$, post-CABG surgery $(5.4 \%, 95 \% \mathrm{CI}-1.1 \%$ to $12.2 \%, n=3)$, or sepsis $(0.8 \%, 95 \%$ CI $-0.8 \%$ to $2.4 \%, n=2$ ). 

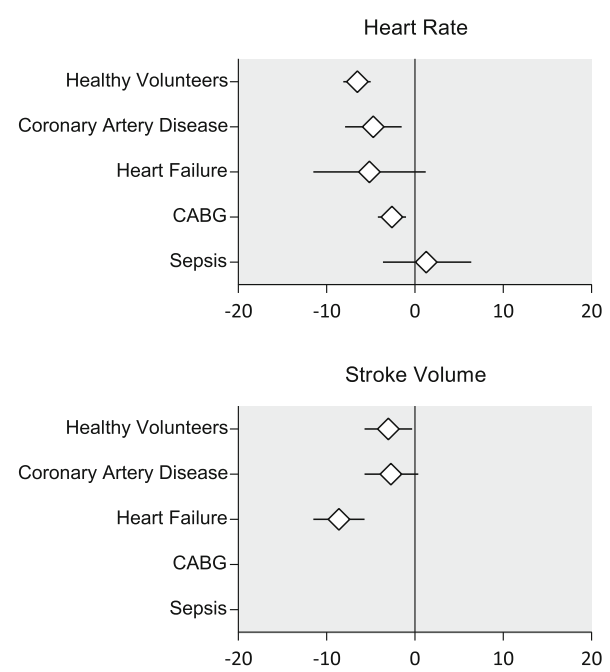

Cardiac Output

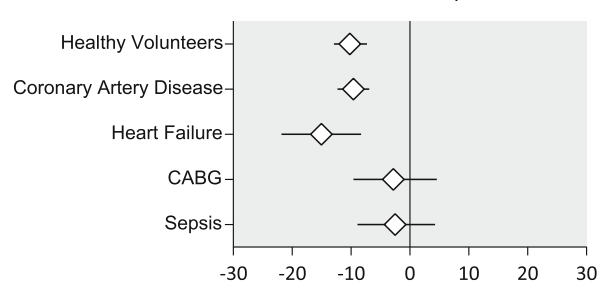

Mean Arterial Pressure

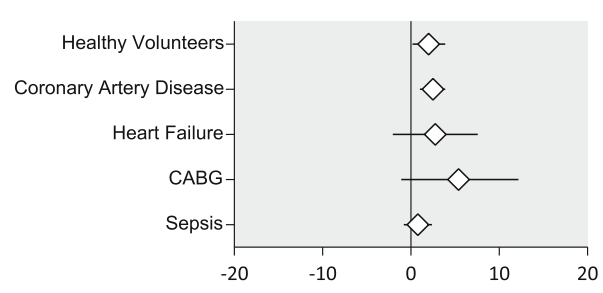

Systemic Vascular Resistance

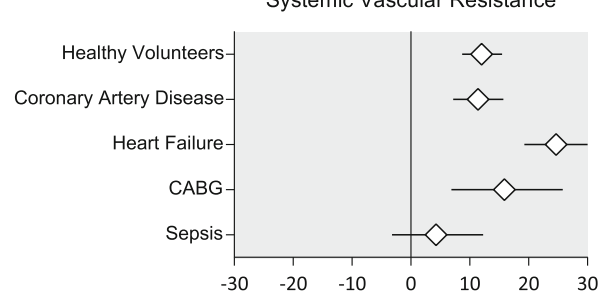

Oxygen Delivery

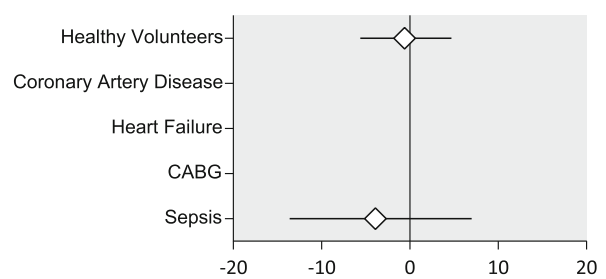

Data sets $\mathbf{S}$
19
6
5
3
2

bjects RoM (\%) $(95 \% \mathrm{Cl})$

256

79

89

45

39

Data sets Subjects

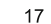

$\mathrm{I}^{2}(\%)(95 \% \mathrm{Cl})$

89 (84 to 92)

82 (62 to 92$)$

98 (96 to 99$)$

0 (0 to 80 )

69 (0 to 93 )

$I^{2}(\%)(95 \% \mathrm{Cl})$

230

89 (84 to 92$)$

$4 \quad 46$

$-2.7(-5.7$ to 0.4$)$

0 (0 to 25$)$

89

$-8.6(-11.5$ to -5.7$)$

44 (0 to 79$)$

Data sets Subjects

RoM (\%) $(95 \% \mathrm{Cl})$

$\mathrm{I}^{2}(\%)(95 \% \mathrm{Cl})$

$18 \quad 201 \quad-10.2(-12.9$ to -7.3$) \quad 73(57$ to 83$)$

$6 \quad 49 \quad-9.6(-12.3$ to -6.9$) \quad 0(0$ to 7$)$

$5 \quad 74 \quad-15.2(-21.7$ to -8.2$) \quad 84(63$ to 93$)$

$3 \quad 45 \quad-2.8(-9.6$ to 4.6$) \quad 69(0$ to 91$)$

$2 \quad 39 \quad-2.5(-8.9$ to 4.3$) \quad 3(0$ to 15$)$

Data sets Subjects $\quad$ RoM $(\%)(95 \% \mathrm{Cl}) \quad I^{2}(\%)(95 \% \mathrm{Cl})$

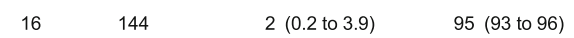

$4 \quad 51 \quad 2.5$ (1.0 to 3.9$) \quad 0$ (0 to 58$)$

$4 \quad 73 \quad 2.7(-2.1$ to 7.7$) \quad 95$ (90 to 97$)$

$3 \quad 45 \quad 5.4(-1.1$ to 12.2$) \quad 94$ (87 to 98$)$

$2 \quad 39 \quad 0.8(-0.8$ to 2.4$) \quad 0(0$ to 90$)$

Data sets Subjects $\operatorname{RoM}(\%)(95 \% \mathrm{Cl}) \quad I^{2}(\%)(95 \% \mathrm{Cl})$

$14 \quad 149 \quad 12.1$ (8.6 to 15.7$) \quad 80$ (68 to 88 )

$5 \quad 70 \quad 11.4(7.2$ to 15.7$) \quad 32(0$ to 74$)$

$5 \quad 89 \quad 24.6(19.3$ to 30.1$) \quad 32(0$ to 74$)$

$3 \quad 45 \quad 15.9$ (6.9 to 25.8$) \quad 53$ (0 to 86 )

$2 \quad 39 \quad 4.3(-3.2$ to 12.3$) \quad 29(0$ to 81$)$

Data sets Subjects $\quad \operatorname{RoM}(\%)(95 \% \mathrm{Cl}) \quad I^{2}(\%)(95 \% \mathrm{Cl})$

$3 \quad 37 \quad-0.6(-5.6$ to 4.7$) \quad 68(0$ to 91$)$

68 (0 to 91$)$

1

0

$3 \quad 53 \quad-3.9(-13.6$ to 7$) \quad 92(79$ to 97$)$

Fig. 2 Summary effect sizes. Results of the meta-analysis of acute hyperoxia-induced changes in heart rate, stroke volume, cardiac output, mean arterial pressure, systemic vascular resistance, and oxygen delivery in healthy volunteers, and patients with coronary artery disease or heart failure, patients after coronary artery bypass graft (CABG) surgery and patients with sepsis. Summary effect sizes are expressed in percentage change from baseline (ratio of means; RoM). Cl confidence interval 
In all patient groups, except for patients with sepsis ( $4.3 \% 95 \%$ CI $-3.2 \%$ to $12.3 \%, n=2$ datasets), hyperoxia increased systemic vascular resistance. In healthy volunteers, and CAD, HF, and CABG patients, the increase was $12.1 \%$ (95\% CI $8.6 \%$ to $15.7 \%, n=14$ ), $11.4 \%$ (95\% CI $7.2 \%$ to $15.7 \%, n=5$ ), $24.6 \%$ ( $95 \%$ CI $19.3 \%$ to $30.1 \%, n=5$ ), and $15.9 \%$ (95\% CI $6.9 \%$ to $25.8 \%, n=3$ ), respectively.

Oxygen delivery did not change in healthy volunteers or septic patients. This variable was not measured in CAD or CABG patients. Only one study measured the effect of hyperoxia on $\mathrm{DO}_{2}$ in patients with heart failure, which showed no change either [22].

\section{Heterogeneity}

As represented by the $I^{2}$ statistic and its 95\% CI intervals, considerable heterogeneity was found in the results for studies with healthy volunteers for all variables, except oxygen delivery. To explore this heterogeneity, we categorized studies based on several characteristics and tested the change in heterogeneity of cardiac output measurements. These categories were exposure time ( $\leq$ $0 \mathrm{~min}, 11-20 \mathrm{~min}$, and $>20 \mathrm{~min}$ ), participant blinding (yes, no/unclear), assessor blinding (yes, no/unclear), and invasiveness of the measurements performed (invasive, noninvasive). Categorization based on the magnitude of the intervention (e.g., $\mathrm{P}_{\mathrm{a}} \mathrm{O}_{2}$ ) was not possible because only five studies reported these values. The modality used to administer oxygen was not considered as an alternative because there is known high variability in the actual $\mathrm{F}_{\mathrm{I}} \mathrm{O}_{2}$ being breathed by the subject, despite using similar masks. Grouping studies with an exposure time $\leq 10$ min resulted in an $I^{2}$ of $0 \%(95 \%$ CI $0 \%$ to $6 \%$, $n=9)$. However, in the two remaining exposure time groups (11-20, $n=7$, and $>20$ min, $n=3$ ) heterogeneity remained high $(78 \%$ and $79 \%$, respectively). For the other characteristics, categorization did not substantially reduce heterogeneity.

As an alternative, we analyzed studies which appeared to deviate substantially from the summary effect estimate in either effect direction or size on probable methodological explanations (for an overview see Additional file 5). Large differences in effect size were mostly associated with ultrasound measurements. In one case almost all subjects were female, and in another the subjects were competitive divers. Although the effect of gender on the hyperoxic response is unknown, divers may have adjusted to hyperoxic oxygen tensions as they are usually exposed to hyperoxia during dives due to the increased pressure under water.

For studies in patients with CAD, heterogeneity was confined to heart rate results $\left(I^{2} 82 \%\right.$, 95\% CI 62\% to $92 \%)$. In these patients, $\mathrm{P}_{\mathrm{a}} \mathrm{O}_{2}$ interacted significantly with the decrease in heart rate $(\beta=-0.03 \% ; p=0.0009)$, meaning that the magnitude of hyperoxia is an important modifier of the effect size. Studies in patients with heart failure showed heterogeneity in results related to changes in heart rate $\left(I^{2} 98 \%, 95 \%\right.$ CI $96 \%$ to $\left.99 \%\right)$, cardiac output ( $I^{2} 84 \%$, $95 \%$ CI $63 \%$ to $93 \%)$, and mean arterial pressure $\left(I^{2} 95 \%\right.$, 95\% CI $90 \%$ to $97 \%$ ). Hyperoxia had variable effects in studies with patients after CABG surgery, as indicated by an $I^{2}$ of $94 \%$ (95\% CI $87 \%$ to $\left.98 \%\right)$. Similarly, high heterogeneity existed between studies in patients with sepsis investigating the effect of oxygen supplementation on oxygen delivery $\left(I^{2} 92 \%, 95 \%\right.$ CI $79 \%$ to $\left.97 \%\right)$. Unfortunately, due to the limited number of studies performed in these patient groups, further exploration of this heterogeneity was not possible.

\section{Discussion}

In this systematic review and meta-analysis, we found that hyperoxia does not increase systemic oxygen delivery in healthy volunteers, heart failure patients, or septic patients. Hyperoxia reduces cardiac output and increases systemic vascular resistance, and slightly increases mean arterial pressure in healthy volunteers or nonhospitalized cardiovascularcompromised patients. In patients with sepsis, hyperoxia does not seem to effect central hemodynamics.

Oxygen supplementation is generally initiated with the intent to increase oxygen availability to cells. However, the present meta-analysis shows that "the more, the better" does not apply to oxygen. In five of the six studies in healthy volunteers [26-28], HF patients [22], and septic patients [29, 30], hyperoxia did not increase systemic oxygen delivery and, in one study with septic patients, hyperoxia even decreased oxygen delivery [10]. Although hypoxic patients benefit from a higher fraction of inspired oxygen, supplementation above normoxia seems to be futile as the hemodynamic response to hyperoxia (decrease in CO, increase in SVR) outbalances the benefit of additionally dissolved oxygen in the blood.

Oxygen inhalation reduced cardiac output by approximately $10 \%$ and increased systemic vascular resistance by $11-12 \%$ in both healthy volunteers and CAD patients. In these groups, the reduced cardiac output is predominantly driven by a reduction in heart rate rather than stroke volume. In heart failure patients, however, cardiac output decreased by $15 \%$ through a reduction in stroke volume instead of heart rate. No change in MAP was found, but SVR increased by $25 \%$. This larger increase could be related to a combination of the increased neurohormonal activity and endothelial dysfunction seen in these patients [31]. In post-CABG surgery patients, there also was a significant increase in SVR, but without the decrease in cardiac output seen in other patients; this resulted in a tendency towards a small increase in MAP. A clear difference between hospitalized and nonhospitalized patients included in this meta-analysis is that the former may have received inotropic and vasoactive support during the study periods (e.g., dopamine 
and norepinephrine). It is, however, unlikely that these affected the results because drug infusion rates were kept constant during the study periods [29, 32-34]. In addition, pharmacological blockade of $\alpha$ - and $\beta$-receptors does not alter the hemodynamic response to hyperoxia in healthy volunteers and hyperoxia does not affect plasma (nor)epinephrine levels [35, 36]. Similarly, in isolated arteries, hyperoxia has no effect on $\alpha$-receptor-mediated constriction [37]. Altogether, heart failure patients seem to be the most sensitive to the negative hemodynamic effects of hyperoxia.

Increases in SVR indicate significant arterial vasoconstriction. In humans, oxygen has been shown to induce vasoconstriction in the coronary [38, 39], brachial [40], retinal $[41,42]$, and cerebral vascular bed. Recent studies of the sublingual microcirculation show that hyperoxia increases heterogeneity of the microcirculation when healthy volunteers [43], CABG patients [34], or a mixed group of ICU patients [44] breathe pure oxygen, with a decrease in perfused vessel density of $15-30 \%$. This parameter reflects the number of vessels that contribute to the exchange of oxygen and nutrients in the microcirculation. These alterations may compromise oxygen delivery on a cellular level, especially when organs are already defunct of proper perfusion due to pre-existing (vascular) pathology. This has been shown in an animal model of coronary stenosis, in which hyperoxic vasoconstriction exacerbated cardiac ischemia [45]. Supplying oxygen to patients with acute myocardial infarction increases infarct size, although it is unclear whether this is primarily due to impaired perfusion, increased generation of reactive oxygen species, or both $[4,46]$. It is important to note that increases in SVR give no indication of the location of vasoconstriction. Some vascular beds may show more constriction than others. For instance, in dogs, hyperoxia increases blood flow to the kidney, liver, and intestines but reduces flow to the myocardium, pancreas, and skeletal muscle [47]. A similar redistribution was seen in pigs with fecal peritonitis and in rats with hemorrhagic shock $[7,8]$.

The absence of an effect of hyperoxia on SVR in septic patients is consistent with the clinical observations of vasoplegia that may occur in these patients. Although only two small studies were performed in this patient population, the lack of an effect on SVR and MAP in these patients questions the postulated beneficial effect of increasing blood pressure without the use of fluid resuscitation or vasopressors. Indeed, a randomized controlled trial which investigated this potential positive effect for patients with septic shock found no change in vasopressor requirements when patients were ventilated with pure oxygen during the first $24 \mathrm{~h}$ of admission [48]. This observation is in line with the result of our meta-analysis.

For most groups and parameters, considerable heterogeneity existed. We believe this is primarily caused by methodological differences. Despite using pure oxygen, the actual administered fraction of oxygen through a mask may vary substantially because of mixing with air in the absence of a perfect seal. Even when using the same mask and ventilation system, intra-individual variation in the resulting arterial oxygen tension can exist, while the hemodynamic response to oxygen seems to be $\mathrm{P}_{\mathrm{a}} \mathrm{O}_{2}$-dependent $[9,27,49-51]$. Because arterial oxygen tensions were not measured in most studies, it was impossible to account for the most obvious and important possible source of heterogeneity. For the patient groups, the number of studies was insufficient to properly investigate heterogeneity. Differences in effect size may also be caused by using measuring methods that are sensitive to small changes in setup or that require additional manual processing, especially when the study is performed in an unblinded fashion. For instance, the studies in healthy volunteers with the largest decrease in stroke volume were performed with handheld ultrasound probes, a technique which is known to be highly sensitive to slight changes in measuring angles. Similarly, a large hyperoxia-induced decrease in systemic oxygen delivery in septic patients was only observed when measuring brachial blood flow with ultrasound. The unblinded study design, in combination with a measuring modality with low reproducibility, may have led to an overestimation of the true effect. On the other hand, the correlation between brachial flow and cardiac index is low, so a regional difference is not excluded. However, for the majority of studies, we do not think the methodological issues (e.g., lack of blinding or randomization) were particularly impactful because of the pre-post-test design and the use of objective endpoints [52].

\section{Conclusion}

The present meta-analysis evaluating pre-post studies shows that there is no evidence supporting the belief that oxygen supplementation in the absence of hypoxemia increases systemic oxygen delivery. Combined with potentially significant decreases in cardiac output and increases in systemic vascular resistance in cardiac-compromised patients, we discourage superfluous oxygen supplementation.

\section{Additional file}

Additional file 1: Search strategy. The search strategies used to search the PubMed and EMBASE strategies for eligible studies. (DOCX $15 \mathrm{~kb}$ )

Additional file 2: Risk of bias tool and analysis. Modified risk of bias tool used to assess the risk of bias in the included studies, along with the results of the risk of bias analysis. (DOCX $109 \mathrm{~kb}$ )

Additional file 3: Adjusted formulae. Formulae used in this meta-analysis, adjusted to include pre-post correlations. (DOCX 20 kb)

Additional file 4: Forest plots per group. Forest plots of the individual studies. (PDF 115 kb) 
Additional file 5: Studies that deviate from the mean. Characteristics of the studies with healthy volunteers which show results that deviate substantially from the mean effect size. (DOCX $27 \mathrm{~kb}$ )

\section{Abbreviations}

CABG: Coronary artery bypass graft; CAD: Coronary artery disease; $\mathrm{Cl}$ : Confidence interval; $\mathrm{CO}$ : Cardiac output; $\mathrm{DO}_{2}$ : Oxygen delivery; $\mathrm{F}_{1} \mathrm{O}_{2}$ : Fraction of inspired oxygen; HF: Heart failure; HR: Heart rate; ICU: Intensive care unit; MAP: Mean arterial pressure; $\mathrm{P}_{2} \mathrm{O}_{2}$ : Arterial partial pressure of oxygen; RoM: Ratio of means; SD: Standard deviation; SEM: Standard error of the mean; SV: Stroke volume; SVR: Systemic vascular resistance

\section{Acknowledgements}

We would like to thank Dr. Friedrich for his help with the ratio of means analysis.

\section{Funding}

The authors received no specific funding for this work.

\section{Availability of data and materials}

The datasets used and/or analyzed during the current study are available from the corresponding author on reasonable request.

\section{Authors' contributions}

BS performed the database search, selected studies, extracted and analyzed the data, and wrote the manuscript. YMS helped with the interpretation of data and critically revised the manuscript. JCvdW helped to analyze and interpret the data and revised the manuscript. HMOvS helped with the interpretation of data and critically revised the manuscript. AMESdM conceived the study design, selected studies, extracted and checked data, and helped to write the manuscript. All authors read and approved the final manuscript.

\section{Ethics approval and consent to participate}

Not applicable.

\section{Consent for publication}

Not applicable.

\section{Competing interests}

The authors declare that they have no competing interests.

\section{Publisher's Note}

Springer Nature remains neutral with regard to jurisdictional claims in published maps and institutional affiliations.

\section{Author details}

'Department of Intensive Care, VU University Medical Center, De Boelelaan 1117, 1007, MB, Amsterdam, the Netherlands. ${ }^{2}$ Department of Internal Medicine, VU University Medical Center, Amsterdam, the Netherlands. ${ }^{3}$ Department of General Practice and Elderly Care Medicine, Amsterdam Public Health research institute, VU University Medical Center, Amsterdam, the Netherlands.

\section{Received: 17 November 2017 Accepted: 26 January 2018}

\section{Published online: 25 February 2018}

\section{References}

1. de Jonge E, Peelen L, Keijzers PJ, Joore H, de Lange D, van der Voort PHJ, et al. Association between administered oxygen, arterial partial oxygen pressure and mortality in mechanically ventilated intensive care unit patients. Crit Care. 2008;12:R156.

2. Kilgannon JH, Jones AE, Shapiro NI, Angelos MG, Milcarek B, Hunter K, et al. Association between arterial hyperoxia following resuscitation from cardiac arrest and in-hospital mortality. JAMA. 2010;303:2165-71.

3. Girardis M, Busani S, Damiani E, Donati A, Rinaldi L, Marudi A, et al. Effect of conservative vs conventional oxygen therapy on mortality among patients in an intensive care unit: the oxygen-ICU randomized clinical trial. JAMA. 2016;316(15):1583-9.

4. Stub D, Smith K, Bernard S, Nehme Z, Stephenson M, Bray JE, et al. Air versus oxygen in ST-segment elevation myocardial infarction. Circulation. 2015;131:2143-50
5. Rønning OM, Guldvog B. Should stroke victims routinely receive supplemental oxygen? A quasi-randomized controlled trial. Stroke. 1999;30:2033-7.

6. Elmer J, Scutella M, Pullalarevu R, Wang B, Vaghasia N, Trzeciak S, et al. The association between hyperoxia and patient outcomes after cardiac arrest: analysis of a high-resolution database. Intensive Care Med. 2015;41:49-57.

7. Bitterman H, Brod V, Weisz G, Kushnir D, Bitterman N. Effects of oxygen on regional hemodynamics in hemorrhagic shock. Am J Phys. 1996;271(1 Pt 2): H203-11.

8. Hauser B, Barth E, Bassi G, Simon F, Groger M, Oter S, et al. Hemodynamic, metabolic, and organ function effects of pure oxygen ventilation during established fecal peritonitis-induced septic shock. Crit Care Med. 2009;37(8):2465-9.

9. Bak Z, Sjoberg F, Rousseau A, Steinvall I, Janerot-Sjoberg B. Human cardiovascular dose-response to supplemental oxygen. Acta Physiol. 2007; 191(1):15-24.

10. Rossi P, Tauzin L, Weiss M, Rostain J-C, Sainty J-M, Boussuges A. Could hyperoxic ventilation impair oxygen delivery in septic patients? Clin Physiol Funct Imaging. 2007;27:180-4.

11. Cornet AD, Kooter AJ, Peters MJ, Smulders YM. The potential harm of oxygen therapy in medical emergencies. Crit Care. 2013;17:313.

12. Calzia E, Asfar P, Hauser B, Matejovic M, Ballestra C, Radermacher P, et al. Hyperoxia may be beneficial. Crit Care Med. 2010;38(10 Suppl):S559-68.

13. Stouffer GA, Klein JL, McLaughlin DP. Cardiovascular Hemodynamics for the Clinician. Chichester, UK: John Wiley \& Sons, Ltd; 2017;

14. Quality assessment tool for before-after (pre-post) studies with no control group. Available from http://www.nhlbi.nih.gov/health-pro/guidelines/indevelop/cardiovascular-risk-reduction/tools/before-after. Accessed Jan 5 2017.

15. Friedrich JO, Adhikari NKJ, Beyene J. Ratio of means for analyzing continuous outcomes in meta-analysis performed as well as mean difference methods. J Clin Epidemiol. 2011;64:556-64.

16. DerSimonian R, Laird N. Meta-analysis in clinical trials. Control Clin Trials. 1986;7:177-88.

17. Huedo-Medina TB, Sánchez-Meca J, Marín-Martínez F, Botella J. Assessing heterogeneity in meta-analysis: Q statistic or $\mathrm{I}^{2}$ index? Psychol Methods. 2006;11:193-206.

18. Neyeloff JL, Fuchs SC, Moreira LB. Meta-analyses and Forest plots using a microsoft excel spreadsheet: step-by-step guide focusing on descriptive data analysis. BMC Res Notes. 2012;5:52.

19. Park JH, Balmain S, Berry C, Morton JJ, McMurray JJ. Potentially detrimental cardiovascular effects of oxygen in patients with chronic left ventricular systolic dysfunction. Heart. 2010;96(7):533-8.

20. Daly WJ, Bondurant S. Effects of oxygen breathing on the heart rate, blood pressure, and cardiac index of normal men-resting, with reactive hyperemia, and after atropine. J Clin Invest. 1962;41:126-32.

21. Thomas M, Malmcrona R, Shillingford J. Haemodynamic effects of oxygen in patients with acute myocardial infarction. Br Heart J. 1965;27:401-7.

22. Daly WJ, Behnke RH. Hemodynamic consequences of oxygen breathing in left ventricular failure. Circulation. 1963;27:252-6.

23. Haneda T, Nakajima T, Shirato K, Onodera S, Takishima T. Effects of oxygen breathing on pulmonary vascular input impedance in patients with pulmonary hypertension. Chest. 1983;83(3):520-7.

24. Packer M, Lee WH, Medina N, Yushak M. Systemic vasoconstrictor effects of oxygen administration in obliterative pulmonary vascular disorders. Am J Cardiol. 1986;57(10):853-8

25. Wagner PD, Laravuso RB, Uhl RR, West JB. Continuous distributions of ventilation-perfusion ratios in normal subjects breathing air and 100 per cent O2. J Clin Invest. 1974:54:54-68.

26. Karetzky MS, Keighley JF, Mithoefer JC. The effect of oxygen administration on gas exchange and cardiopulmonary function in normal subjects. Respir Physiol. 1971;12:361-70.

27. Bodetoft S, Carlsson M, Arheden H, Ekelund U. Effects of oxygen inhalation on cardiac output, coronary blood flow and oxygen delivery in healthy individuals, assessed with MRI. Eur J Emerg Med. 2011;18:25-30.

28. Andersen A, Hillestad L. Hemodynamic responses to oxygen breathing and the effect of pharmacological blockade. Acta Med Scand. 1970;188(5):419-24.

29. Reinhart K, Bloos F, König F, Bredle D, Hannemann L. Reversible decrease of oxygen consumption by hyperoxia. Chest. 1991;99:690-4.

30. Reinhart K, Spies CD, Meier-Hellmann A, Bredle DL, Hannemann L, Specht $\mathrm{M}$, et al. $\mathrm{N}$-acetylcysteine preserves oxygen consumption and gastric mucosal pH during hyperoxic ventilation. Am J Respir Crit Care Med. 1995; 151(3 Pt 1):773-9. 
31. Watson AM, Hood SG, May CN. Mechanisms of sympathetic activation in heart failure. Clin Exp Pharmacol Physiol. 2006;33:1269-74.

32. Kuttila K. Response of tissue oxygenation to systemic hyperoxia after cardiac surgery. Crit Care Med. 1990;18(4):369-72.

33. Harten JM, Anderson KJ, Kinsella J, Higgins MJ. Normobaric hyperoxia reduces cardiac index in patients after coronary artery bypass surgery. J Cardiothorac Vasc Anesth. 2005;19:173-5.

34. Helmerhorst HJF, de Wilde RBP, Lee DH, Palmen M, Jansen JRC, van Westerloo DJ, et al. Hemodynamic effects of short-term hyperoxia after coronary artery bypass grafting. Ann Intensive Care. 2017;7:20.

35. Gole Y, Gargne O, Coulange M, Steinberg JG, Bouhaddi M, Jammes Y, et al. Hyperoxia-induced alterations in cardiovascular function and autonomic control during return to normoxic breathing. Eur J Appl Physiol. 2011;111: 937-46.

36. Yamazaki F, Takahara K, Sone R, Johnson JM. Influence of hyperoxia on skin vasomotor control in normothermic and heat-stressed humans. J Appl Physiol. 2007;103:2026-33.

37. Kalsner S. Intrinsic prostaglandin release. A mediator of anoxia-induced relaxation in an isolated coronary artery preparation. Blood Vessels. 1976;13: 155-66.

38. McNulty PH, Robertson BJ, Tulli MA, Hess J, Harach LA, Scott S, et al. Effect of hyperoxia and vitamin $C$ on coronary blood flow in patients with ischemic heart disease. J Appl Physiol. 2007;102(5):2040-5.

39. Ishikawa K, Kanamasa K, Tashi M, Yamakado T, Hayashi T, Katori R. Coronary artery constriction by oxygen breathing in patients with coronary disease. Tohoku J Exp Med. 1981;134(3):265-71.

40. Frobert $\mathrm{O}$, Holmager $\mathrm{P}$, Jensen KM, Schmidt EB, Simonsen U. Effect of acute changes in oxygen tension on flow-mediated dilation. Relation to cardiovascular risk. Scand Cardiovasc J. 2008;42(1):38-47.

41. Halloran M, Donoghue E, Dainty C. Measurement of the retinal arteriolar response to a hyperoxic provocation in nonsmokers and smokers, using a high-resolution confocal scanning laser ophthalmoscope. J Biomed Opt. 2014;19(7):76012.

42. Olafsdottir OB, Eliasdottir TS, Kristjansdottir JV, Hardarson SH, Stefansson E. Retinal vessel oxygen saturation during 100\% oxygen breathing in healthy individuals. PLoS One. 2015;10(6):e0128780.

43. Orbegozo Cortés D, Puflea F, Donadello K, Taccone FS, Gottin L, Creteur J, et al. Normobaric hyperoxia alters the microcirculation in healthy volunteers. Microvasc Res. 2015;98:23-8.

44. Donati A, Damiani E, Zuccari S, Domizi R, Scorcella C, Girardis M, et al. Effects of short-term hyperoxia on erythropoietin levels and microcirculation in critically III patients: a prospective observational pilot study. BMC Anesthesiol. 2017;17:49

45. Guensch DP, Fischer K, Shie N, Lebel J, Friedrich MG. Hyperoxia exacerbates myocardial ischemia in the presence of acute coronary artery stenosis in swine. Circ Cardiovasc Interv. 2015;8:e002928.

46. McGuinness SP, Parke RL, Drummond K, Willcox T, Bailey M, Kruger C, et al. A Multicenter, randomized, controlled phase llb trial of avoidance of hyperoxemia during cardiopulmonary bypass. Anesthesiology. 2016;125:465-73.

47. Meier J, Hutter J, Pape A, Kleen M, Kemming G, Habler O, et al. Regional blood flow during hyperoxic haemodilution. Clin Physiol Funct Imaging. 2005;25(3):158-65.

48. Asfar P, Schortgen F, Boisramé-Helms J, Charpentier J, Guérot E, Megarbane $B$, et al. Hyperoxia and hypertonic saline in patients with septic shock (HYPERS2S): a two-by-two factorial, multicentre, randomised, clinical trial. Lancet Respir Med. 2017;5:180-90.

49. Foster GL, Casten GG, Reeves TJ. The effects of oxygen breathing in patients with acute myocardial infarction. Cardiovasc Res. 1969;3:179-89.

50. Saadjian A, Paganelli F, Levy S. Hemodynamic response to oxygen administration in chronic heart failure: role of chemoreflexes. J Cardiovasc Pharmacol. 1999;33(1):144-50.

51. Haque WA, Boehmer J, Clemson BS, Leuenberger UA, Silber DH, Sinoway LI. Hemodynamic effects of supplemental oxygen administration in congestive heart failure. J Am Coll Cardiol. 1996;27:353-7.

52. Wood L, Egger M, Gluud LL, Schulz KF, Jüni P, Altman DG, et al. Empirical evidence of bias in treatment effect estimates in controlled trials with different interventions and outcomes: meta-epidemiological study. BMJ. 2008;336:601-5.

53. Barratt-Boyes BG, Wood EH. Cardiac output and related measurements and pressure values in the right heart and associated vessels, together with an analysis of the hemo-dynamic response to the inhalation of high oxygen mixtures in healthy subjects. J Lab Clin Med. 1958;51(1):72-90.

54. Kenmure AC, Murdoch WR, Hutton I, Cameron AJ. Hemodynamic effects of oxygen at 1 and 2 Ata pressure in healthy subjects. J Appl Physiol. 1972; 32(2):223-6.

55. Harten JM, Anderson KJ, Angerson WJ, Booth MG, Kinsella J. The effect of normobaric hyperoxia on cardiac index in healthy awake volunteers. Anaesthesia. 2003;58:885-8.

56. Smit HJ, Vonk-Noordegraaf A, Marcus JT, Van Der Weijden S, Postmus PE, De Vries PMJM, et al. Pulmonary vascular responses to hypoxia and hyperoxia in healthy volunteers and COPD patients measured by electrical impedance tomography. Chest. 2003;123:1803-9.

57. Waring WS, Thomson AJ, Adwani SH, Rosseel AJ, Potter JF, Webb DJ, et al. Cardiovascular effects of acute oxygen administration in healthy adults. J Cardiovasc Pharmacol. 2003;42:245-50.

58. Anderson KJ, Harten JM, Booth MG, Kinsella J. The cardiovascular effects of inspired oxygen fraction in anaesthetized patients. Eur J Anaesthesiol. 2005; 22(6):420-5.

59. Rousseau A, Bak Z, Janerot-Sjöberg B, Sjöberg F, Janerot-Sjoberg B, Sjoberg $F$. Acute hyperoxaemia-induced effects on regional blood flow, oxygen consumption and central circulation in man. Acta Physiol Scand. 2005; 183(3):231-40

60. Ley S, Puderbach M, Risse F, Ley-Zaporozhan J, Eichinger M, Takenaka D, et al. Impact of oxygen inhalation on the pulmonary circulation: assessment by magnetic resonance (MR)-perfusion and MR-flow measurements. Investig Radiol. 2007:42:283-90.

61. Kim YK, Jun IG, Kim SR, Hwang JH, Cho SK, Han SM, et al. Using 100\% oxygen does not alter the cardiovascular autonomic regulation during noninvasively simulated haemorrhage in healthy volunteers. J Int Med Res. 2008;36(2):227-36

62. Gao Z, Spilk S, Momen A, Muller MD, Leuenberger UA, Sinoway LI. Vitamin $C$ prevents hyperoxia-mediated coronary vasoconstriction and impairment of myocardial function in healthy subjects. Eur J Appl Physiol. 2012;112(2): 483-92.

63. Sinski M, Lewandowski J, Przybylski J, Zalewski P, Symonides B, Abramczyk $P$, et al. Deactivation of carotid body chemoreceptors by hyperoxia decreases blood pressure in hypertensive patients. Hypertens Res. 2014; 37(9):858-62.

64. Fagoni N, Sivieri A, Antonutto G, Moia C, Taboni A, Bringard A, et al. Cardiovascular responses to dry resting apnoeas in elite divers while breathing pure oxygen. Respir Physiol Neurobiol. 2015;219:1-8.

65. Ganz W, Donoso R, Marcus H, Swan HJ. Coronary hemodynamics and myocardial oxygen metabolism during oxygen breathing in patients with and without coronary artery disease. Circulation. 1972;45(4):763-8.

66. Lecerof $\mathrm{H}$. Central haemodynamics during oxygen breathing in angina pectoris. Thorax. 1974;29(6):673-7.

67. Mak S, Azevedo ER, Liu PP, Newton GE. Effect of hyperoxia on left ventricular function and filling pressures in patients with and without congestive heart failure. Chest. 2001;120:467-73.

\section{Submit your next manuscript to BioMed Central and we will help you at every step:}

- We accept pre-submission inquiries

- Our selector tool helps you to find the most relevant journal

- We provide round the clock customer support

- Convenient online submission

- Thorough peer review

- Inclusion in PubMed and all major indexing services

- Maximum visibility for your research

Submit your manuscript at www.biomedcentral.com/submit 